Historic, Archive Document

Do not assume content reflects current scientific knowledge, policies, or practices. 



\section{LILIUM MYRIOPHYLLUM}

(Regale)

\section{Royal Lily of China}

One of the finest Garden Lilies ever introduced in America. Its History, Origin, and Culture Instructions compiled by

BAUM'S HOME OF FLOWERS, Knoxville, Tennessee

\&

\section{DESCRIPTION}

A most beautiful creamy white bloom with bright golden throat; outside of flower white tinted yellow at the base with delicate purple midribs, having three wide petals and three narrow petals; beautiful rich green foliage, very wiry stem, growing from eighteen inches to three feet tall, producing sometimes as many as eight or ten blooms to the bulb. A rival to the Jasamine in fragrance. The bloom will last for days after being cut, having wonderful

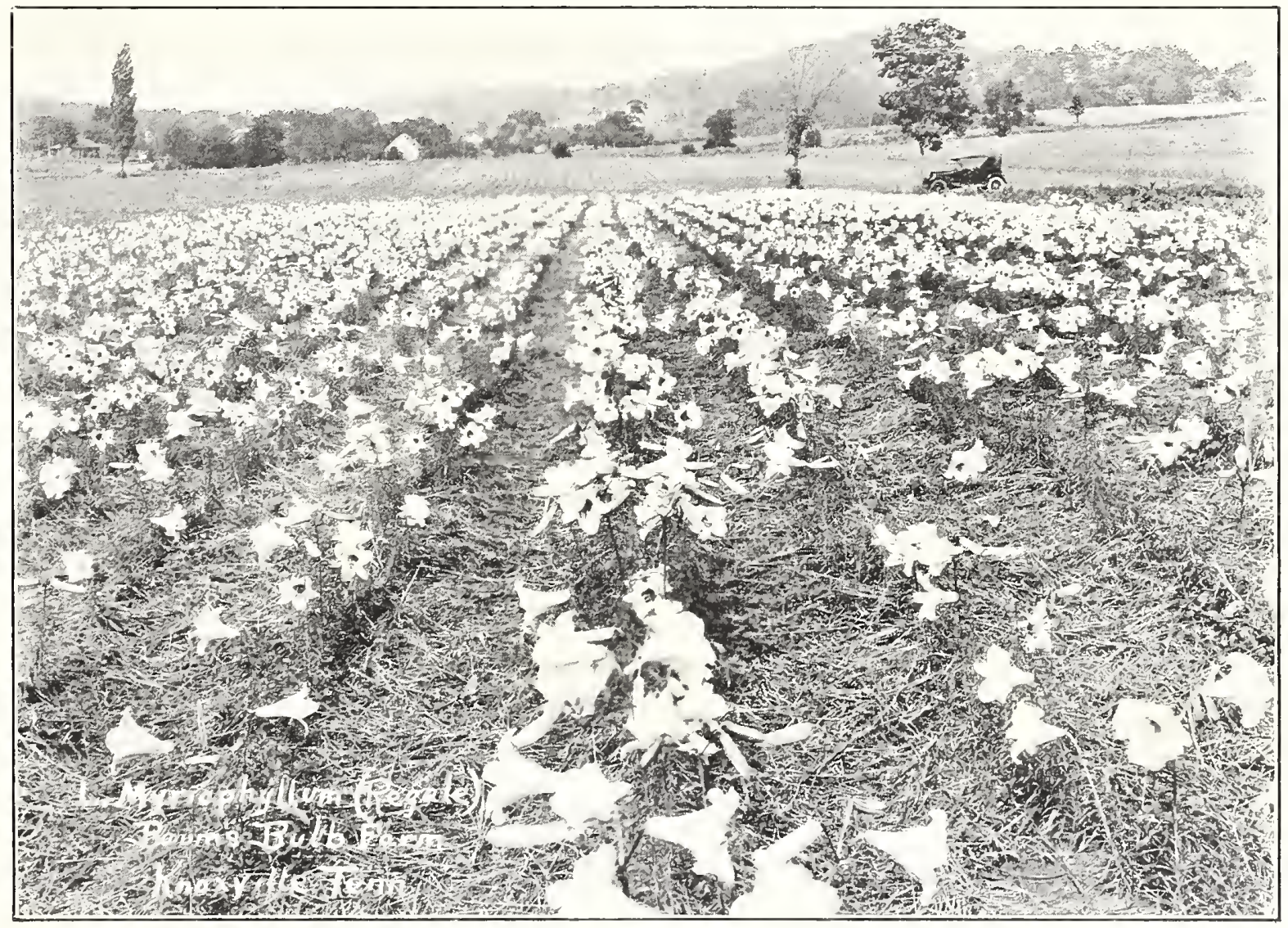


substance, perfectly hardy and will thrive and do well in any good rich garden loam, either partially shade or all sun, but it is very essential that the soil be well drained. This lily will not thrive in a location where water ocassionly stands or in tight mucky soil.

\section{CULTURE FOR FORCING}

Regale Lilies can be easily forced if properly handler. Any good greenhouse soil, the same as used for Gig Lilies is desirable. Immediately upon planting, place them upon top of bench, as it is necessary that the tops and root action start together, keeping them well watered and in a temperature of from fiftytwo to fifty-eight degrees, feeding from time to time is permissible, using any good bone meal or liquid manure. As this lily is a natural hybrid, better results will be obtained if only one bulb is planted to each pot. If planted in December they will easily come in bloom for Easter if properly handled. We have had success with the above culture, but can not guarantes results.

\section{SEED CULTURE}

Sow in hotbeds in December or January; drill the seed in rows in a well-pulverized, light, sandy soil. Care must be exercised in water- ing the young seedlings when they come up, as they have a tendency to damp-off. Dusting from time to time with grape dust will prevent this. After they make their second or third leaves and the weather becomes warm, you can take off the glass sash and cover with slats during the summer months. Dig these seedlings late in the Fall, as the leaves begin to ripen, and plant back immediately in beds from three to six inches deep and from five to six inches apart, according to weather conditions in your locality.

We have never discovered any disease in these bulbs, after successfully producing same for the last seven years. We have made shipments of both Seed and Bulbs to every State in the United States, several provinces in Canada, England and Germany, and without any complaint on reproduction of same. We believe this lily will eventually be grown in every garden and by every Florist in the country.

The following articles appeared in "The Country Gentleman" of October, 1925, by Dr. E. H. Wilson of the Arnold Arboratum, Harvard University, Jamaica Plain, Massachusetts, who was the introducer of this lily to America which will give you the authentic history of this lily direct from the introducer.

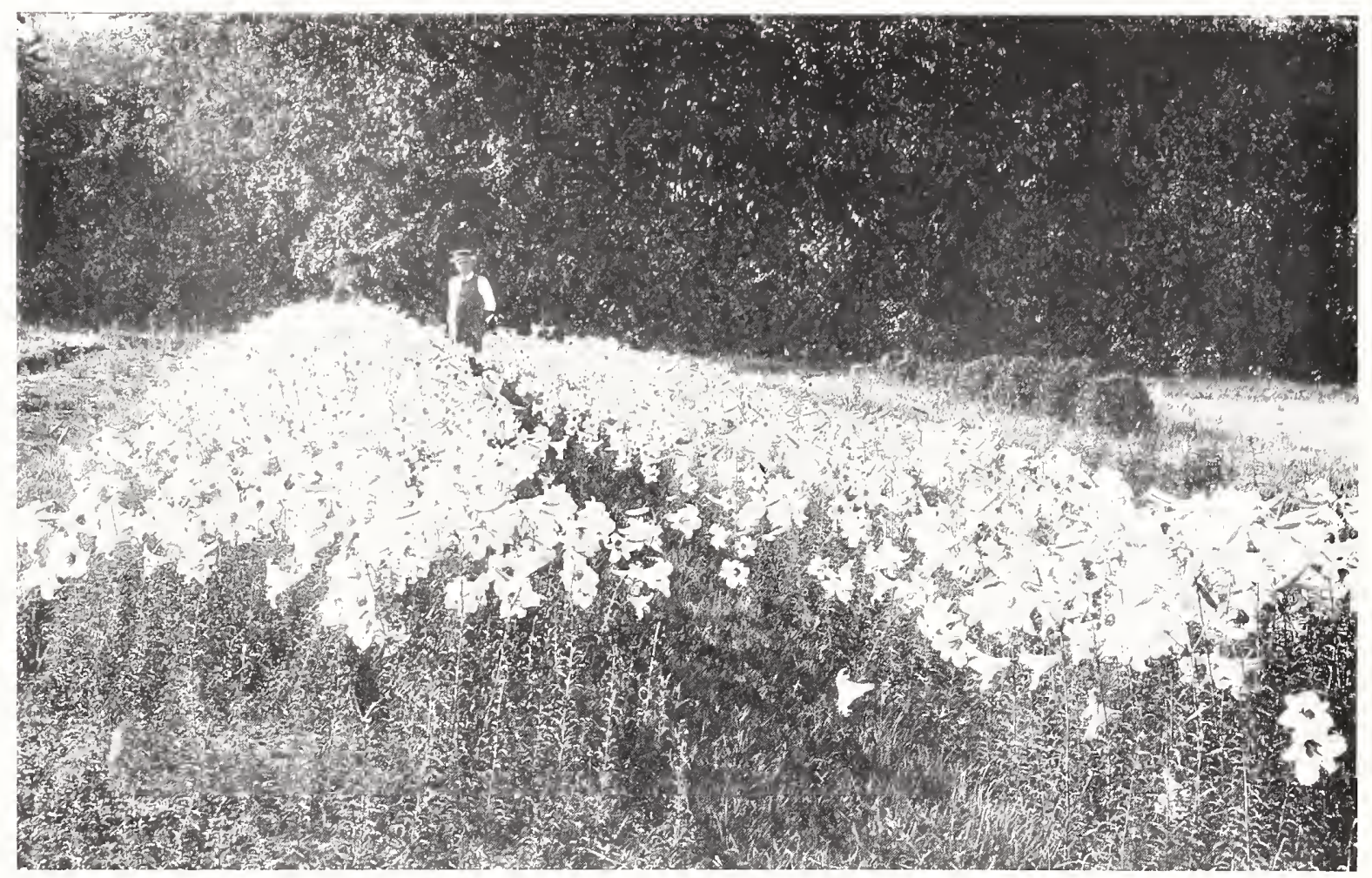

The Regale Lily in a Massachusetts Garden 


\section{Price of the Regale Lily}

\section{A Treasure Irested Grom Grorbidding Tibet}

\author{
By E. H. WILson
}

How many people know the size of the mule's hoof? Quite a number have felt the strength of a mule's leg and the sharpness of his teeth, and his obstinacy is a proverb. But the size of his hoof is another matter.

Frankly I do not know with mathematical exactness, but as I lay on the ground and more than forty of these animals stepped over my prostrate form the hoof seemed enormous, blotting out my view of the heavens. The instinctive sure-footedness of the mule is well known and I realized it with graditude as these animals one by one passed over me and not one even frayed my clothing.

It happened in the no-man's land of the Chino-Tibetan borderland and my predicament had been brought about by a rockslide, a very common occurrence in that part of the world. I had left Boston, Massachusetts, at the end of March, 1910, and having crossed to Europe, reached Peking by way of the Trans-Siberian Railway early in May. From Peking I traveled by devious routes across China to Sungpang Ting, in the extreme west-northwest of Chma, which was reached toward the end of August.

\section{NATURE'S JOKE}

My quest was the Regale lily which I had discovered some years earlier but had failed to introduce successfully into American gardens. Its beauty and richness of fragrance had won my heart and I was determined that it should grace the gardens of the Western world.

That such a rare jewel should have its home in so remote and arid a region of the world seemed like a joke on Nature's part. However, there it was and my business in life was to effect its transference to lands where its beauty would find proper recognition.

Throughout an indefinite past, generations of the

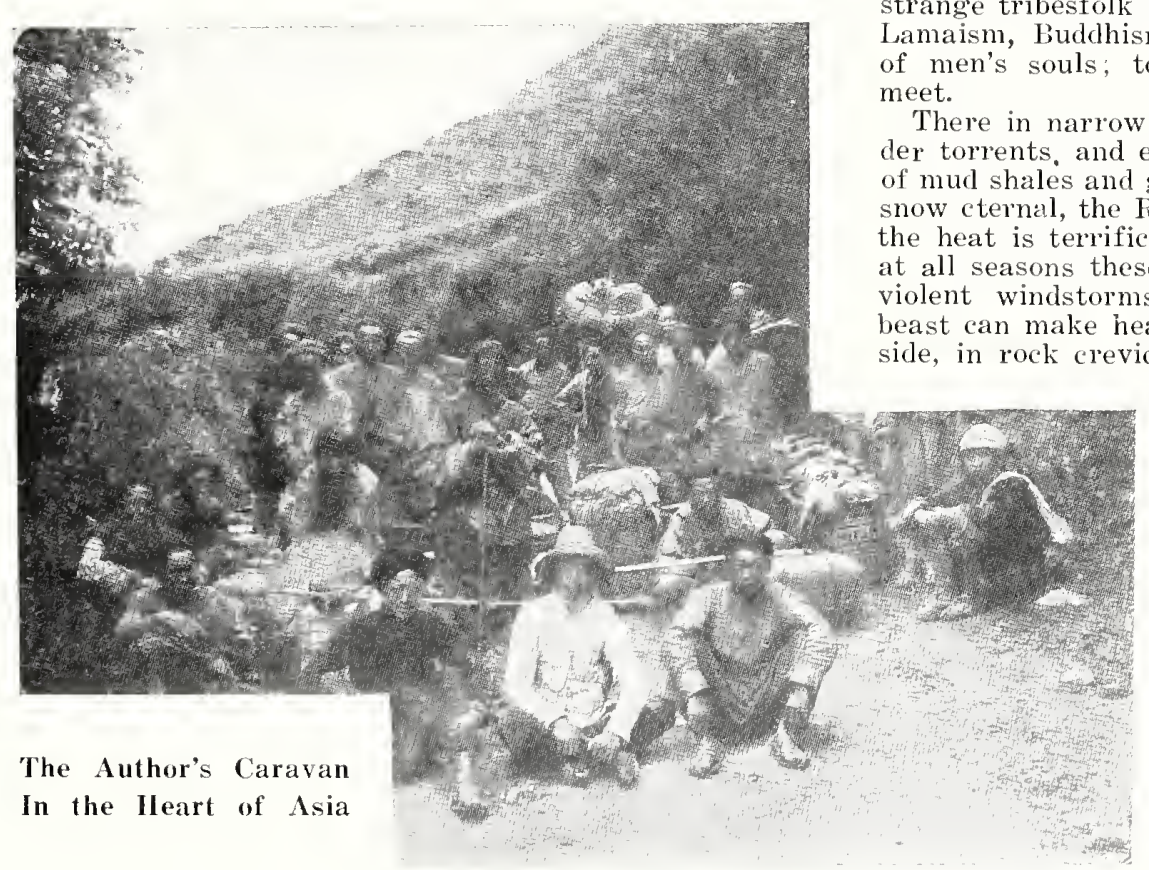

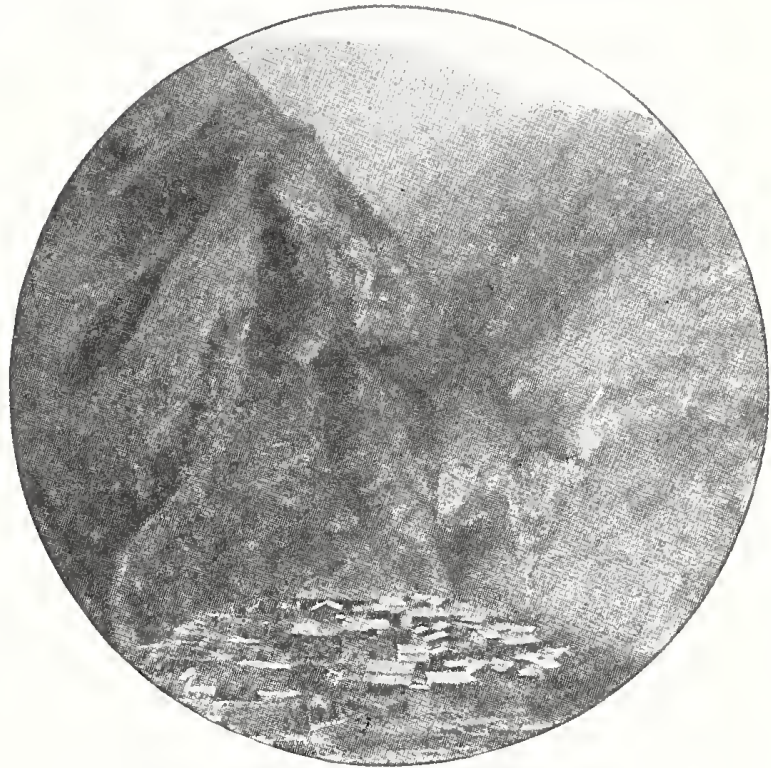

A Place Near Where the Rock Slide Occurred

Regale lily had lived unsung and unseen save by the rude peasants of a rude land. But few white men had passed that way when first I made discovery and none had noted my royal lady. This had been preserved for me.

And what of the Regale lily?

Journey in thought with me for a moment or two, westward, until "west" becomes "east," although we still chase the setting sun. Across the broad American continent, across that wide ocean misnamed "Pacific" to Shanghai, the gate of Far Cathay; onward and westward up the mighty Yangtsze River for 1800 miles, then northward up its tributary, the Min, some 250 miles to the confines of mysterious Tibet; to that little-known hinterland which separates China proper from the hierarchy of Lhasa; to the wild and mountainous country peopled mainly by strange tribesfolk of unknown origin; to a land where Lamaism, Buddhism and Phallism strive for mastery of men's souls; to a region where mighty empires meet.

w semiarid valleys, down which thuin and encompassed by mountains composed granite whose peaks are clothed with the heat is terrific in winter the cold is intense, and at all seasons these valleys are subject to sudden and violent windstorms against which neither man nor beast can make headway. There in June, by the way up on the mountainside and precipice this lily in full bloom greets the weary wayfarer.

Not in two's and three's, but in hundreds, in thousands-aye, in tens of thousands. Its slender stems, aach from two to four feet tall, flexible and tense as steel, overtop the coarse grasses and scrub and are crowned with one to several large funnel-shaped flowers, each more or less wine colored without, pure white and lustrous on the face, clear canary yellow within the tube and each stamen filament tipped with a golden anther. 


\section{A FAIRYLAND}

The air in the cool of the morning and in the evening is laden with delicious perfumes exhaled from cvery blossom. For a brief season this lily transforms a lonely, semi-desert region into a veritable fairyland.

Sungpang Ting is a military town situated on the hearlwaters of the Min River. It is a very important outpost of Chincse civilization and a trade center of considerable magnitude. Merlicines in great variety, including the famous rhubarb and musk, are brought in by tribesfolk from the neighboring mountains and bartered to Chinese merchants.

Rested and reprovisioned I and my followers sallied forth and for seven consecutive days plunged down the seemingly interminab'e gorge of the Min River.

It was frightfully hot and traveling was most fatiguing In many places the narrow track was hewn and blasted from solid rock and here and there tunneling had been necessary. In several places Chinese characters of huge size and carved in the rocks warned those who could interpret them of the danger's of the road and urged all not to tarry inparticular places.

There was much traffic, largcly coolies, but alsoseveral mule trains taking up brick tea and cotton cloth in particular and various merchandise in general, and bringing down medicines, hides, deer horns.

The passing of mule trains was a difficult business, often possible only at particular places when one caravan canie to a standstill and allowed the other to pass.

The eighth day I camped and for several days was busy arranging to sccure in October, the proper season of the year, some six or seven thousand bulbs of the Regale lily. Plans completed we set out for Chengtu Fu, the capital city of Szechuan.

The hardships of a four month's journey were bc ginning to tell on me and dysentery in a mild form had troubled me for days. Yet it was with a light heart and a satisfied mind that I rode in my chair. Soon after starting we passed a mule train brcaking camp and bound our way.

\section{A HAIRBREADTH ESCAPE}

We werc making good progress, ny chair leading with personal attendants and man carrying my large camera immediately behind, my black spaniel dog wagging his tail ahcad of us all.

Song was in our hearts when I noticed my dog suddenly cease wagging his tail, cringe and rush forward. A small piece of rock hit the path and rebounded into the river 300 feet below. A rock slicle was upon us. I shouted an order and the bearers put down the chair. The two front bearers ran forward and I essaycd to follow.

Just as I cleared the chair handles a large boulder crashed into the body of the chair and turned it over and down to the river it was hurled. I ran-a few yards more and 1 would be under the lee of hard rock. But I was bowled over, tried to jump up, found my right leg was uscless, so crawled forward to the shclter of the cliff.

It was only a small slide and we had had a providential cscape. My right leg was broken in two places below the knee and the side of my calf was badly lacerated.

With the legs of my camera tripod I improvised splints, and while these were being bandaged to my leg the mule caravan, passed in the morning, loomed into view. The road was too narrow for them to turn back and they dare not stand still since we knew not when the rock slide would recommence. There was only one thing to do. I lay across the road and the mules stepped over my body.

Then it was that I realized the sizc of the mule's hoof.

The men salvaged my wrecked chair and we started on our journey to Chengtu Fu. We made it in threc days, and three agonizing days they were for me.

WORTH MORE THAN THEY COST

At Clengtu I was carried to the house of Dr. W. H. Davidson, of the Friends' Foreign Mission, and all that could be done was done. The leg had become infected. In spite of every care at the end of six weeks there were no signs of the bones uniting. The question of amputation was pressed, but somehow I never felt this would be necessary. Other doctors were called in, including a distinguished French army surgeon named Doctor Mouillac. Some cutting and splitting was donc and the infection stayed.

The leg is erooked, fifteen-sixteenths of an inch short, but is sound and has since carried me many thousands of miles.

The accident notwithstanding, I got my Regale lily 
and brought the bulbs safely to Boston. The bulbs were incased in clay, packed in charcoal, shipped at silk rates and reached Boston a few days after myself. Planted in a garden in Roslindale, Massachusetts, they flowered freely in the June following and some even ripened seeds.

From this stock has sprung the millions now happily acclimated in American gardens and other gardens across the seas in Europe. Each year it adds to the pleasure of millions of folk. The price I paid has been stated. The Regale lily was worth it and more. Proud am I to have discovered, introduced and christened the Regale lily. Did what?

"God forgive me! No, I didn't.

'Tis God's present to our gardens.

Anyborly might have found it but-

His whisper came to me!"

(With apologies to Kipling.)

-Reproduced from "Country Gentleman" Oct., 1925.

\section{LILIUM REGALE TRIED AS FORCER}

\section{By DAVID GRIFFITHS}

In the fow year $\rightarrow$ since its introduction to commercial growers, the Regal lily has made rapid progress in favor for out-door plantings. Under glass, however, success with it has been by no means uniform. For that reason the suggestion given here by the government expert should be welcome.

The foreing quality of the Regal lily, Lilium Regale or L, Myriophyllum, seems to be still in considerable dispute, some growers maintaining stoutly that it forces easily and other good growers testifying that they have failed with it. Evidently suggestions are in order, and many grower's will have to cut loose from methods employed with other lilies and try to get acquainter with this item. A brief note on last winter's experience will be of interest and assistance to those who have stock for foreing this winter and happen to be in somewhat of an experimental mood.

Last Autumn there was at the trial grounds of the United States Department of Agriculture at Arlington Farm, Va, a narrow bed, consisting of four rows, six inches apart, which had been planted six or more seeds to the inch with a garden drill November 1, 1921. The bed had been undisturbed, except the weeds had been kept out since the planting. As will be readily appreciated, the plants were thick and, consequently, the bulbs were smaller than normal for 2-year-old stock. An estimate inclicated bulbs at the rate of fifty or more to eighteen inches of row. In spite of this, the blooming was profuse in 1923; and all the blooms in the four rows, six inches apart and 130 feet long. werc pollinated and allowed to produce all the seed possible.

\section{ONE LOT OF SPECIAL INTEREST}

January 10, 1524, after a heavy freeze, which was the first to reach the bulbs, a small portion of this planting was dug and the bulbs were potted up, Checks were used, and the several lots were handled in different ways at various times during the winter, but it is not the intention to go into detail now. There is one lot that is of special interest and gives a hint on what is actually necessary to succed with this lily under glass.

The next day after potting up, one lot of these bulbs was put in a constant temperature of 70 to 80 degrees. January 21st top growth was in evidence, and March 15 th the first flowers opened. All of the plants floweled within five days' time. So far as it goes, this substantiates the contention of Charles $L$. Baum that the nlace to root this lily is on top of the benches in full heat. It must be admitted that this is pretty heroic treatment, but it apvears to be the one which most nearly fits the reauirements. Even with this high heat, no flowers failed to open.

In spite of the high degree of heat, the flower's were remarkably satisfactory, but not normally firm. Doubtless 65 to 70 degrees would give firmer flowers, and it

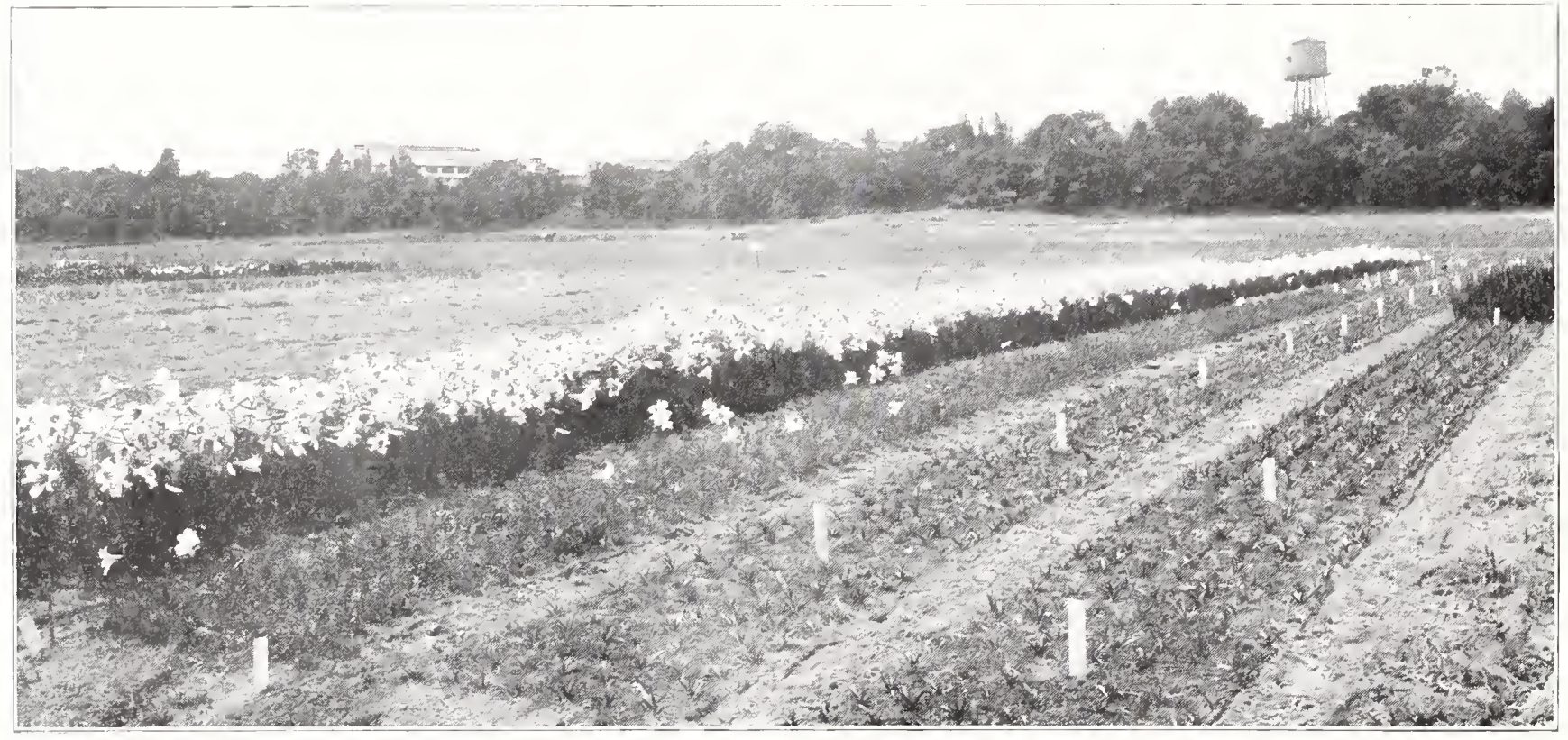

Beds of Lilium Regale from Seed at Government Experiment Grounds, Arlington Farm, Va. 


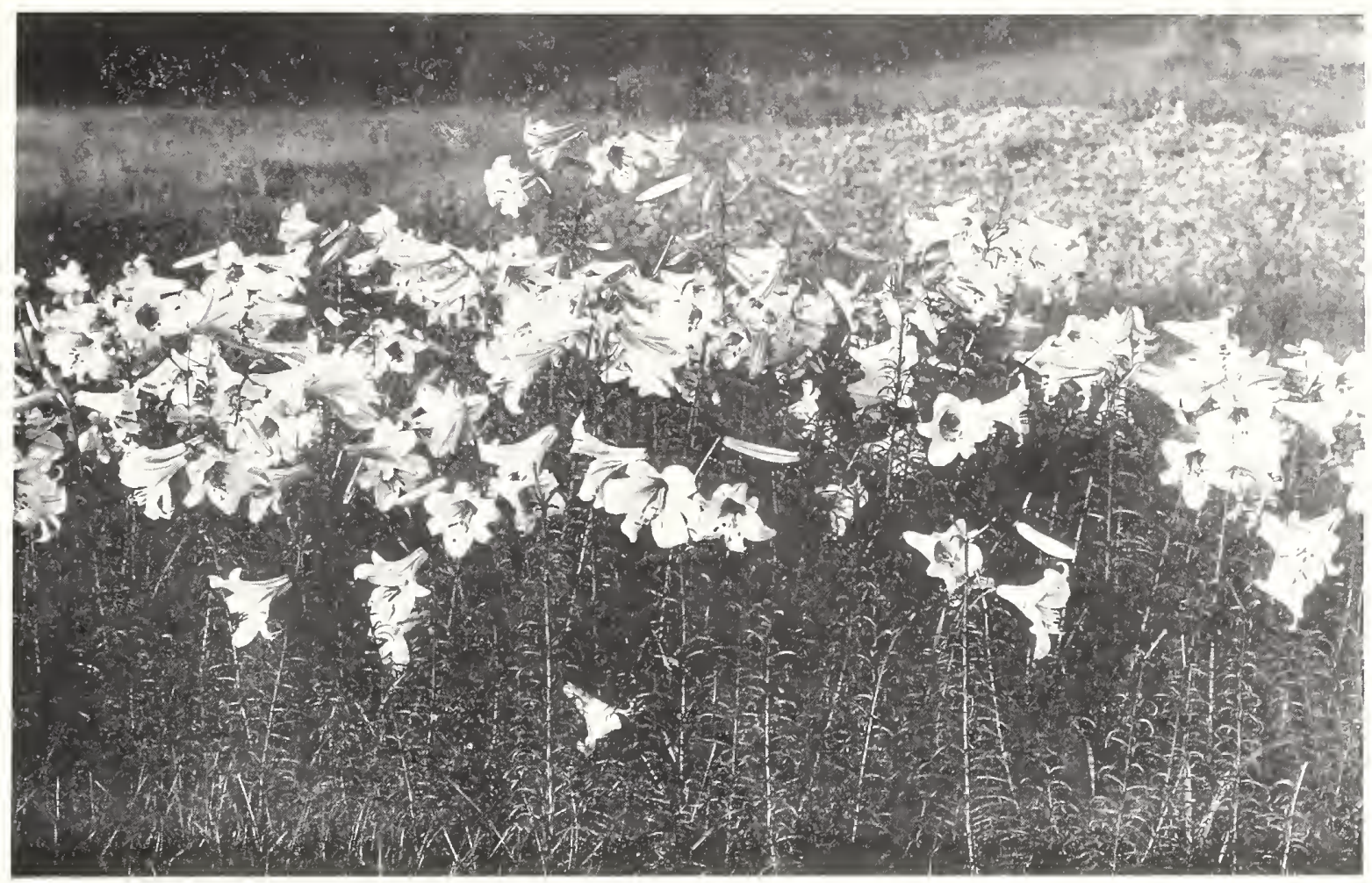

Another Clump of Specimens

is probable that ninety days' time will bring this lily to flower in good condition without an preparatory period to estaolish a root system. In this test a good suppiy but not over-supply, of moisture without sogginess, was maintained, and the plants were syringed daily. Proper watering seems to require as much skill alid judgment with this lily as with Lilium Longiflorum.

It would seem that the shortage of foreign bulos and the uncertainty of foreign bulbs and the uncertainty of transportation facilities which have obtained in the recent past on the soreign article need not worry us much a few years hence, when our grower's have had time to work up stocks re this lily.

It will be noted that the bulbs used here were from seed sown in the fall. Success with this kind of seed- ling has been experienced consistently at Washington, D. C., until the winter of 1923-1924. This was a flat failure. It is thought that the open winter furnished conditions which allowed germination, followed by cold enough weather to kill the young seedlings. A, all events, the seed was rotted by spring: Other growers also report failures with autumn seedling.

The illustration on Page 5 shows a 3-foot bed of the regal lily the third year from seed, the bulbs in which had been transplanted at the beginning of the third growing season. Immediately in front of it is a bed of younger stock, seed of which was plantor in late May, 1923, and the bulbs transplanted in the spring of 1924 . The photograph was taken the last of June, 1924. There are a few blooms on the younger stocks, fourteen months from seed.

\section{A TESTIMONIAL REGARDING THE KEEPING QUALITIES OF THE REGALE LIL}

We made a shipment of cut Regale Lily buds from Knoxville to Max Schling, Florist of New York City, on June 9, 1923. This shipment went forward on train No. 42, leaving Knoxville at 2:45 p. m., June 9th; arriving in New York City on the morning of June 13th. Shipment delayed in transit 24 hours.

We received a letter from Mr. Schling which is as follows:

"I received the lilies shipped by you with a little delay on the 13th. They all came in fine condition, some of them half open, some of them buds just breaking, and a few hours after being put in water it could not be noticed how far they had traveled.

A few of the flowers which I took home with me as a try-out are, on June 19th, still in perfect condition and will last for two or three days longer.

Lilium Regale, I would say, is a wonderful acouisition to the retail florist business."

$$
\begin{aligned}
& \text { (signed) Yours very truly, } \\
& \text { Max Schling. }
\end{aligned}
$$

We have experimented in storing Regale Buds and found that they keep very satisfactorily for six or eight weeks which is a continued testimonial that this is a wonderful lily, and is one of the finest commercial summer and garden flowers in existence.

If you are interested in purchasing bulbs or seed of this lily, we will be glad to send you our quotations.

\section{BAUM'S HOME OF FLOWERS KNOXVILLE, TENNESSEE}

